\title{
Reduction of the Toxicity of Fenitrothion to Prawns by Piperonyl Butoxide
}

\author{
Kunio Kobayashi, ${ }^{* 1}$ Yang Wang, ${ }^{* 1}$ Nobuyoshi Imada,*1 \\ Yuji Oshima, ${ }^{* 1}$ and Rizald Max Rompas*: \\ (Received November 13, 1992)
}

\begin{abstract}
The effectiveness of piperonyl butoxide (PB) in reducing the mortality of striped prawn and kuruma prawn during exposure to fenitrothion (FS) was examined. The $24-\mathrm{h} \mathrm{LC}_{30}$ values of $\mathrm{PB}$ for striped and kuruma prawns were 3.5 and $1.6 \mathrm{ppm}$ at $25^{\circ} \mathrm{C}$, respectively. Therefore, PB-treatment for both prawns was conducted at $0.25 \mathrm{ppm}$, corresponding to one-tenth of the mean of both 24-h $\mathrm{LC}_{30}$ values.

The PB-pretreatment before FS-exposure and also the addition of PB to FS-water were effective in decreasing the FS-toxicity to both prawns. The most effective reduction of the toxicity to the prawns was obtained by continuous PB-treatment before and during FS-exposure, resulting in extensions of $50 \%$ survival time by 4-6 times in striped prawn and 10-16 times in kuruma prawn, compared with the respective control groups non-treated with $\mathrm{PB}$.
\end{abstract}

In our previous papers, ${ }^{1-4)}$ it has been demonstrated that the extremely high mortality of kuruma prawn during exposure to fenitrothion (dimethyl 3-methyl-4-nitrophenyl phosphorothionate; FS) is mainly due to fenitrooxon (FO) converted from FS in vivo, ${ }^{-3}$ which displays a high acetylcholinesterase inhibition compared with FS. ${ }^{\text {? }}$ Therefore, it is supposed that reducing the biotransformation of FS to FO may result in decreasd mortality of the prawn in FS-media.

Since Nakatsugawa and Dahm ${ }^{5)}$ demonstrated that piperonyl butoxide (PB) inhibited NADPHand oxygen-dependent hydrolysis of parathion by rabbit liver microsomes, a number of studies have been made of the effects of $P B$ on the disposition of various pesticides in many species of animal. The hydrolysis of di-2-ethylhexyl phthalate by rainbow trout was also inhibited to a large extent by treatment with PB. ${ }^{\text {) }}$

The present study was carried out to examine the effectiveness of $\mathrm{PB}$ in reducing the mortality of two species of fresh- and salt-water prawns, i.e. striped prawn Palaemon paucidens and kuruma prawn Penaeus japonicus, during exposure to FS which has been widely used in Japan as a typical organophosphorus insecticide.

\section{Materials and Methods}

\section{Special Chemicals}

FS was purchased from Wako Pure Chemical Industries, Ltd. and PB from Tokyo Kasei Kogyo Co., Ltd.

\section{Toxicity of Piperonyl Butoxide to Prawns}

First, the toxicity of PB to both test prawns was investigated. Groups of 20 juveniles of each prawn ( $c a .30 \mathrm{mg}$ in body weight) were exposed to $10 l$ of PB-media at $0.1,0.25,0.5,1,2.5,5,10$, and $20 \mathrm{ppm}$ levels for $24 \mathrm{~h}$ at $25^{\circ} \mathrm{C}$ with aeration. PB was dispersed into both fresh and sea water with Tween 80 amounting to 10 times in weight. The chlorinity of sea water used in this experiment was $17 \%$.

\section{Pretreatment Condition of Piperonyl Butoxide for Prawns}

Striped prawn juveniles (ca. $30 \mathrm{mg}$ in body weight) were treated with $0.25 \mathrm{ppm}$ PB-water for $24 \mathrm{~h}$. After PB-treatment, groups of twenty juveniles were exposed to $10 l$ of 5,10 , and $20 \mathrm{ppb}$ FSmedia for $24 \mathrm{~h}$ at $25^{\circ} \mathrm{C}$ with aeration. Another group of juveniles without PB-pretreatment was also subjected to a FS-toxicity test as control.

*1 Laboratory of Fisheries Environmental Science, Faculty of Agriculture, Kyushu University, Hakozaki, Higashi, Fukuoka 812, Japan (小林邦男, 汪陆, 今日信良, 大嶋雄治: 九州大学農学部水雇增殖環境 学教室).

*2 Faculty of Fisheries, Sam Ratulangi University, Manado, North Celebes, Code Pos 95115, Indonesia. 
After the above confirmation of the effectiveness of $P B$ in reducing FS-toxicity to the prawn, a subsequent experiment was carried out to find the optimum time of PB-pretreatment for prawns.

Striped prawn juveniles ( $c a .30 \mathrm{mg}$ in body weight) were treated with $0.25 \mathrm{ppm}$ PB-water for $6,12,24$, and $48 \mathrm{~h}$, and then exposed to 5,10 , and 20 ppb FS-media in a similar way to that mentioned above. Kuruma prawns ( $c a .2 .5 \mathrm{~g}$ in body weight) were pretreated with PB-sea water for 6 , 12 , and $24 \mathrm{~h}$, and then exposed to $10 \mathrm{ppb}$ FS-sea water containing PB $(0.25 \mathrm{ppm})$. FS was dispersed into both fresh and sea water with Tween 80 amounting to 20 times in weight.

\section{Effect of Piperonyl Butoxide on Fenitrothion- Toxicity to Prawns}

Striped prawn juveniles $(\mathrm{ca} .90 \mathrm{mg}$ in body weight) and kuruma prawn juveniles (ca. $50 \mathrm{mg}$ in body weight) were pretreated with $0.25 \mathrm{ppm}$ PBwater for $12 \mathrm{~h}$, and then exposed to FS-media (5, $10,20 \mathrm{ppb}$ ) with and without the addition of $\mathrm{PB}$ $(0.25 \mathrm{ppm})$ for $24 \mathrm{~h}$ at $25^{\circ} \mathrm{C}$.

\section{Results and Discussion}

Toxicity of Piperonyl Butoxide to Prawns

From the data shown in Fig. 1, the 24-h $\mathrm{LC}_{30}$ values of $\mathrm{PB}$ for striped and kuruma prawns are calculated as 3.5 and $1.6 \mathrm{ppm}$ at $25^{\circ} \mathrm{C}$, respectively.

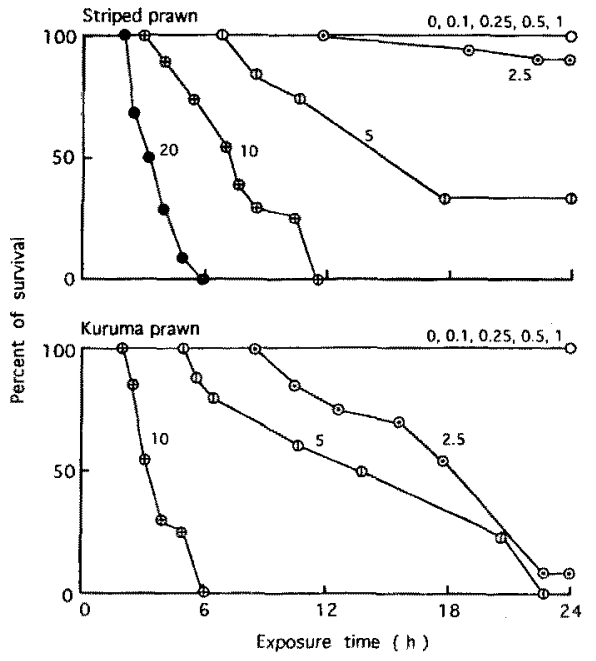

Fig. 1. Toxicity of piperonyl butoxide (PB) to striped prawn and kuruma prawn.

The values in the figures express the concentrations (ppm) of $\mathrm{PB}$ in media.

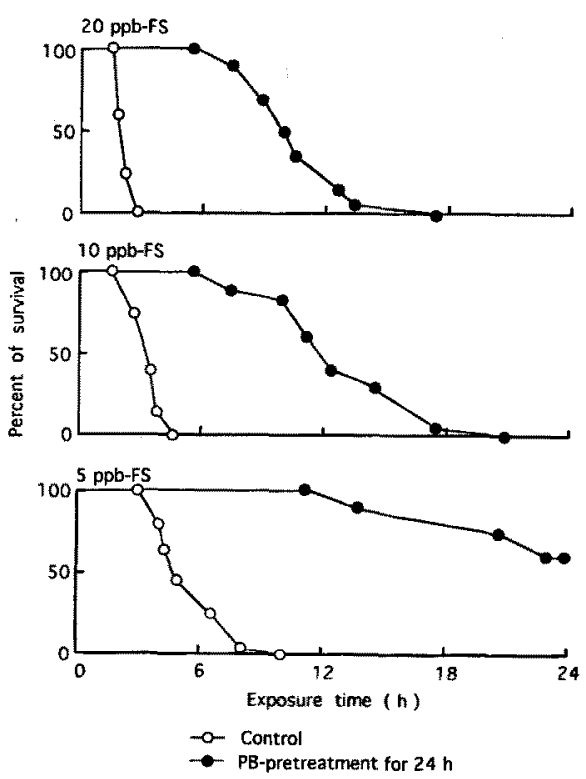

Fig. 2. Effect of piperonyl butoxide (PB: $0.25 \mathrm{ppm}$ ) pretreatment on the toxicity of fenitrothion (FS: $5,10,20 \mathrm{ppb}$ ) to striped prawn.

Therefore, the concentration of PB in the subsequent experiments was set up at $0.25 \mathrm{ppm}$, corresponding to one-tenth of the mean of both $\mathrm{LC}_{50}$ values.

\section{Pretreatment Condition of Piperonyl Butoxide for Prawns}

As shown in Fig. 2, the 50\% survival time of striped prawn exposed to FS-media $(10,20 \mathrm{ppb})$ was extended by 4-5 times by the PB-pretreatment for $24 \mathrm{~h}$. The $50 \%$ survival time of the control group exposed to 5 ppb FS-medium was $c a$. $5 \mathrm{~h}$ and all of the juveniles died within $10 \mathrm{~h}$, whereas $60 \%$ of the PB-treated juveniles survived even after 24-h exposure.

Figure 3 shows the effect of PB-pretreatment time on the reduction of FS-toxicity to striped prawn. Although a reverse of survival time was observed between 12-h and 24-h PB-treated groups, the survival time of the prawn was generally extended with the increase of PB-pretreatment time, resulting in an extension of $50 \%$ survival time by ca. 5 times at 48-h compared with the control.

As shown in Fig. 4, the most effective reduction of FS-toxicity to kuruma prawn was observed in the group which was pretreated with $0.25 \mathrm{ppm}$ PB-sea water for $12 \mathrm{~h}$ and then exposed to FS- 

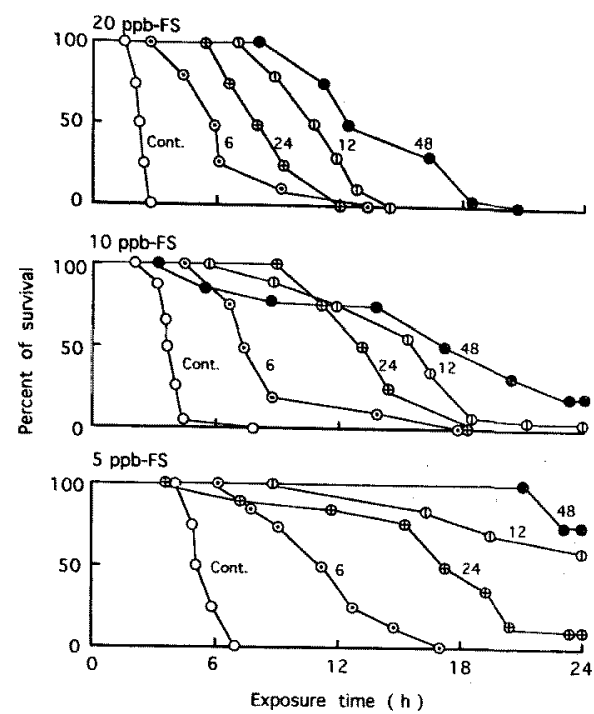

Fig. 3. Effect of piperonyl butoxide (PB: $0.25 \mathrm{ppm}$ ) pretreatment time on the toxicity of fenitrothion (FS: 5, 10, $20 \mathrm{ppb}$ ) to striped prawn.

The values in the figures express PB-pretreatment time (h).

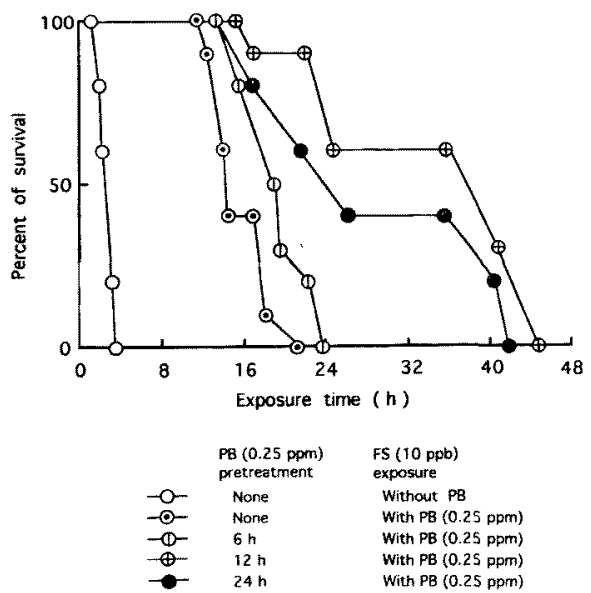

Fig. 4. Effect of piperonyl butoxide (PB) pretreatment time on the toxicity of fenitrothion (FS) to kuruma prawn.

medium containing $0.25 \mathrm{ppm} \mathrm{PB}$, resulting in the prolongation of survival time by $c a .16$ times over that of the control. The addition of PB to FS-sea water for the group without PB-pretreatment was also effective in extending the survival time of kuruma prawn. From these results, the PB-pretreatment time for both prawns was set at $12 \mathrm{~h}$ in
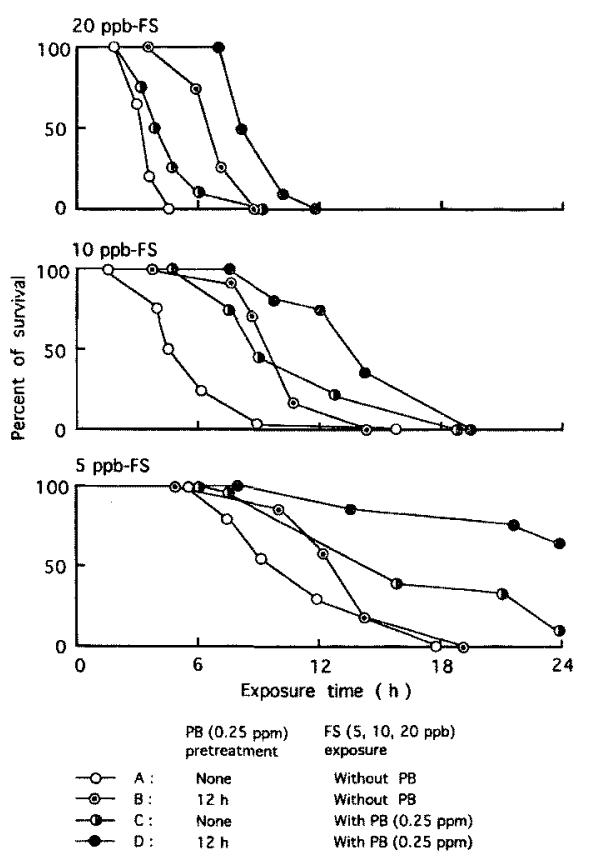

Fig. 5. Effect of piperonyl butoxide (PB) on the toxicity of fenitrothion (FS) to striped prawn.

the subsequent experiment.

Effect of Piperonyl Butoxide on FenitrothionToxicity to Prawns

As shown in Figs. 5 and 6 , the most effective extension of survival time in both prawns was observed in groups (D) which were treated with $\mathrm{PB}$ before and during FS-exposure. The PB-treatment was more effective in reducing FS-toxicity to kuruma prawn compared with that to striped prawn, i.e. the survival time of kuruma prawn (group D) was extended by approximately 13 times over that of the control in 10 ppb FS-medium and no mortality was observed in 5 and 2 ppb FSmedia for $24 \mathrm{~h}$, whereas the survival time of striped prawn (group D) was extended by only 3 times in 10 and $20 \mathrm{ppb}$ FS-media.

The more effective reduction of FS-toxicity to kuruma prawn compared with that to striped prawn might be due to the higher biotransformation of FS to FO in kuruma prawn than that in striped prawn. This presumption is also supported by the short $50 \%$ survival times of control kuruma prawn in 5 and $10 \mathrm{ppb}$ FS (4 and $1.8 \mathrm{~h}$ ) compared with those of control striped prawn in the same media (10 and $4.5 \mathrm{~h}$ ). 


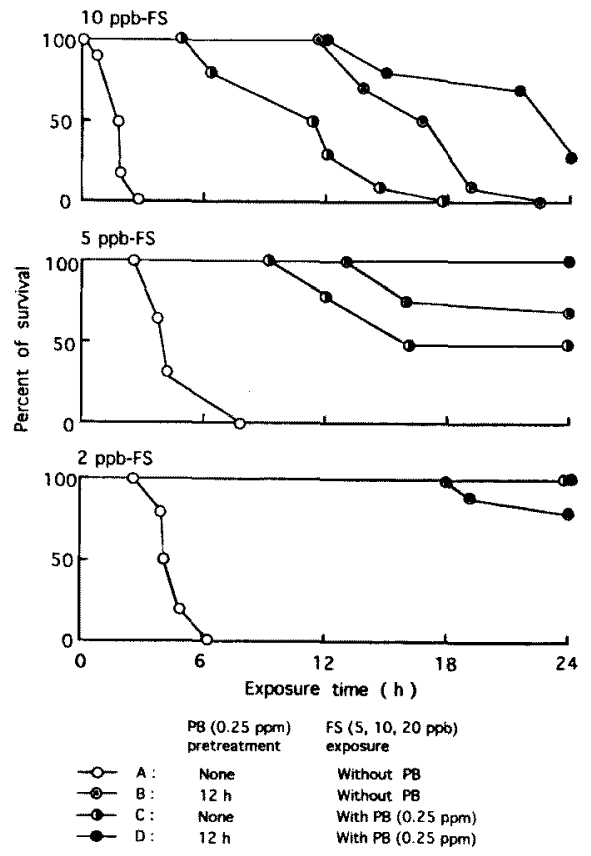

Fig. 6. Effect of piperonyl butoxide (PB) on the toxicity of fenitrothion (FS) to kuruma prawn.

The survival time between group (B) which was exposed to FS-media (PB-free) after PB-pretreatment and group (C) which was exposed to FSmedia containing PB without PB-pretreatment was compared in both prawns. In striped prawn, group (B) showed a longer survival time than group (C) in $20 \mathrm{ppb} F S$, but the situation was reversed after $10-\mathrm{h}$ and 12 -h exposure in 10 and 5 ppb FS, respectively. On the other hand, group (B) in kuruma prawn showed a longer survival time than group (C) in 10 and $5 \mathrm{ppb}$ FS throughout the 24-h exposure. In $2 \mathrm{ppb}$ FS-medium, however, group (B) showed $20 \%$ mortality at $24-\mathrm{h}$, while no mortality was observed in group (C) or in group (D) which was treated with PB before and during FS-exposure.

These results suggest that $\mathrm{PB}$-pretreatment is effective in extending the survival time of prawns in rather high concentrations of FS due to a delay in reaching a lethal level of $\mathrm{FO}$ in vivo in a short period, whereas in low concentrations of FS the addition of PB into the FS-media was more effective compared with PB-pretreatment. This is because it takes time to reach a lethal level of FO in vivo, while the duration of $\mathrm{PB}$ accumulated in the prawns by PB-pretreatment is not so long, as in the case of rats. Kimura et al. ${ }^{72}$ reported that the tissue concentrations of PB orally administered to rats reached the highest values at several hours after dosing, and then gradually decreased, resulting in no detection of $\mathrm{PB}$ in almost all tissues except adipose ones at 24-h.

Therefore, the most effective reduction of the toxicity of organophosphorothionates to prawns must be obtained by the continuous treatment of inhibitors against oxidative desulfurase such as PB, especially in prawns which have a high activity of this enzyme.

\section{Acknowledgements}

We wish to express our sincere thanks to Fukuoka Prefectural Marine Culture Center for the offer of kuruma prawn juveniles.

\section{References}

1) K. Kobayashi, Y. Nakamura, and N. Imada: Metabolism of an organophosphorus insecticide, fenitrothion, in tiger shrimp Penaeus japonicus. Nippon Suisan Gakkaishi, 51, 599-603 (1985).

2) K. Kobayashi, Y. Nakamura, R. M. Rompas, and N. Imada: Difference in lethal concentration in vivo between fenitrothion and its oxo-form in tiger shrimp Penaeus japonicus. Nippon Suisan Gakkaishi, 52, 287-292 (1986).

3) K. Kobayashi, R. M. Rompas, T. Maekawa, N. Imada, and Y. Oshima: Changes in metabolic activity of tiger shrimp larvae at different stages to fenitrothion, an organophosphorus insecticide. Nippon Suisan Gakkaishi, 56, $489-496$ (1990).

4) R. M. Rompas, K. Kobayashi, Y. Oshima, N. Imada, K. Yamato, and Y. Mitsuyasu: Relationship between toxicity and acetylcholinesterase inhibition of some thiono- and oxoform organophosphates in tiger shrimp larvae at different stages. Nippon Suisan Gakkaishi, 55, 669-673 (1989).

5) T. Nakatsugawa and P. A. Dahm: Microsomal metabolism of parathion. Biochem. Pharmac., 16, 25-38 (1967).

6) M.J. Melancon, Jr., J. Saybolt, and J.J. Lech: Effect of piperonyl butoxide on disposition of di-2-ethylhexyl phthalate by rainbow trout. Xenobiotica, 7, 633-640 (1977).

7) R. Kimura, H. Deguchi, and T. Murata: Absorption, distribution and excretion of piperonyl butoxide in rats. Shokuhin Eisci Gakkaishi, 24, 319-323 (1983) (in Japanese). 